IHE ABUSES AND USES OF VENESECTION IN THE PRACTICE OF MEDICINE.*

ROBERT REYBURN, A.M., M.D.

Dean and Professor of Hygiene and Preventive Medicine, Medical Department Howard University.

WASHINGTON, D. C.

Though for centuries venesection was considered one of the most valuable methods to be employed in the cure of disease, it has now fallen entirely out of use.

The present generation of physicians, indeed, has seen so little of the practice of blood letting as a therapeutic agent that it is hard for them to realize how universally it was used even as late as the middle of the last century.

At the time the writer commenced the study of medicine (about fifty years ago) the favorite text-book used by medical students was Watson's "Practice of Medicine." It was indeed a charming book, and one that for beauty of style and literary diction could not be surpassed. It was, however, in some respects a most discouraging book. Watson would give the most vivid pictures of the symptoms and progress of diseases and yet when it came to their treatment all diseases were apparently treated in nearly the same way. His favorite method for the curing of nearly every inflammatory disease was practically limited to the administration of calomel or other mercurials and the free use of bleeding and blistering.

As I read this book I used to ask myself: Is it possible that our means of treating the physical ills of our patients are limited to the use of the above three methods, and its seemed to me that if such was the case then the practice of medicine was a delusion and a failure.

Fortunately, about this time (1853) I procured a copy of $J$. Hughes Bennett's great work on clinical medicine. I received from that book a light and illumination on my studies in the science of medicine that I never had before.

Bennett was a great clinical teacher and reasoner, and while he used bloodletting in a moderate degree, yet he combined with it the literal use of nourishing diet and stimulants. Like the immortal Graves, he was far ahead of his time. Graves was the man who at a time when all the physicians of his time were bleeding and starving their fever patients, dared to feed those liberally under his care. Dr. Graves asked that when he died they should carve on his tombstone, "Here lies the man who fed fevers."

The picture given by te Sage in his immortal book, "Gil Blas," of the character of Dr. Sangrado probably aided largely in calling attention to the absurdity and harmfulness of the free blood letting, so much used by the physicians of that day.

In Gil Blas there is one exquisite piece of satire that we must quote. During a time of great sickness and mortality the notary is sent for to make the will of a sick man. He immediately asks the question, who is the attending physician? On being informed that it was Dr. Sangrado, he at once says they must hurry and lose no time, for if they do not there will be no opportunity to make the will.

Physicians seemed in that day to regard the inflammations of an organ as a monster that had taken possession of the part and that could be destroyed by the abstraction of blood from the veins or by blistering and the administration of mercurials.

* Read before the Medical Society of the District of Columbia, Feb. 26,1003 .
The more accurate knowledge of our day (though still incomplete) has shown us that most, if not all, of the phenomena manifested in the course of the acute inflammations are due to the efforts of the organism to defend itself from the inroads of micro-organisms or the toxins produced by them. We know now, also, that no inflammatory disease can be suddenly cut short by any method of treatment. What we can do, however, is to guide it to a favorable termination.

Admitting, therefore, the utter failure of venesection as a means of cutting short or of curing acute inflammations, the question then arises, were our ancestors in the practice of medicine entirely mistaken in their practice of this now forgotten remedial agent? We should remember that this method of practice was employed by many of the brightest lights of our profession. The physicians of former times were just as acute observers of diseases as those who practice medicine now.

Have we then not lost something of value to our science in our entire abandonment of the practice of venesection? Are there not cases even now that would be benefited by blood letting, and have we not gone from one extreme to another in utterly abjuring it?

Arthur Helps, the great English essayist, says that when a man attempts to avoid error on one side he is very apt to fall into the opposite error. The pendulum of truth is apt to vibrate from the error on this to that of the opposing side.

There are now a considerable number of the members of our profession who believe that while the idea of cutting short an acute inflammation by blood letting is an absurdity, yet in certain diseases venesection is a valuable therapeutic measure, and in some cases is absolutely necessary to preserve the life of the patient.

\section{VENESECTION IN CEREBRAL ENGORGEMENT.}

The class of cases benefited by the abstraction of blood are chiefly those in which there is an abnormal blood pressure in the body which endangers the rupture of a blood ressel in the brain or causes a stasis of blood in some vital organ. Let me give an illustrative case:

Mrs. G., aged 56, was placed under my care a few months ago, for the following symptoms: First, a feeling of numb. ness of the right side of body, involving both upper and lower right extremities, persistent headache, more marked on left side; the headache increased in severity; then she felt very giddy on altempting to walk; her speech then became affected and articulation imperfect. On examining her, I found her to be a stout plethoric woman who had always enjoyed good health, and weighing about 170 or 180 pounds.

She had always been accustomed to living on a farm, and had usually been working a good deal in the open air. For about a year before I saw her, she had changed her occupation to indoor work. She was in fact during that period employed in taking care of an invalid lady and had remained a great deal indoors, very rarely leaving the house. She generally had enjoyed hel food and had usually eaten a liberal supply of meat and nourishing food, and no doubt had partaken of more nutriment than her system needed.

Here was a plain case of threatened cerebral apoplexy, and she became very much alarmed (and with reason) as to her condition. Here was a woman past the menopause and having not the relief that menstruation might have given to the overfilled blood vessels, a woman suffering from a hyperemia with threatened fatal results on account of the degeneration of the cerebral blood vessels which to a greater or lesser degree must be expected at her age. Now would any physician hesitate to bleed in such a case as the above? The proper treatment in such a case is to bleed freely from the arm, 
twelve or sixteen ounces of blood, and follow this by brisk purging with saline purgatives and low diet. Such a case can be brought (as was this one) from the jaws of death by the proper treatment such as outlined above.

$$
\text { BLOOD LETTING IN PNEUMONIA. }
$$

Another disease in which bleeding is sometimes necessary to prevent death is acute or croupous pneumonia. In its great fatality in our day acute pneumonia is a standing disgrace to the practice of medicine.

There can be no question that acute croupous pneumonia is worse treated and the percentage of mortality from it greater than it was thirty or forty years ago. This is admitted by all modern writers on the subject, and it will only be necessary here to give a few references to prove the above statement.

The nestor of American medicine, Dr. N. S. Davis, ${ }^{1}$ says "the mortality in pneumonia has increased during the past forty-five years." The Philadelphia Medical News (March 6, 1897) says mortality from pneumonia has increased during the past fifty years. In New York City out of the 41,000 deaths occurring in 1896 5,383, or nearly one-eighth, died of pneumonia. The mortality from pneumonia in New York City hospital during the period beginning 1834 and ending 1843 was 25.4 per cent., during 1844 to 185325.7 per cent., 1854 to 186323.8 per cent., 1864 to 187027.7 per cent., $187 \%$ to 188638.8 per cent., 1887 to 189534.7 per cent. •

Dr. Putnam ${ }^{2}$ of Boston says pneumonia mortality has increased 50 per cent. during the past thirty years. American Medicine (May 18, 1901, p. 277) says pneumonia is more fatal than tuberculosis. In New York City, from 1890 to 1900 there were 56,092 deaths from pneumonia and 50,490 during the same period from tuberculosis. In Chicago during the same period there were 25,228 deaths from pneumonia and 22,957 deaths from tuberculosis. The following extract is taken from The Journal of the American Medical Association (Jan. 24, 1903) :

THE INCREASING PNEUMONIA MORTALITY.

Nearly three years ago we called attention to the fact that statisties showed that pneumonia was causing more deaths than tuberculosis. We believe that we were the first to eall attention to this fact, but it is becoming generally recognized.

The eircular issued by the Health Department of Chicago for the week ending Jan. 17, 1903, begins with the statement: "Since the census year 1900 pneumonia has claimed more than one-eighth of all the victims of the Grisly Reaper in Chicago; one-third more than consumption, and 46 per cent. more than all other contagious and infectious diseases combined, including diphtheria, erysipelas, influenza, measles, puerperal fever, scarlet fever, smallpox, typhoid fever and whooping cough, the total of which deaths was 4,489 as compared with a total of 6,562 deaths from pneumonia." This statement is a striking one and certainly confirms our earlier assertions as to the predominance of pneumonia over other infectious diseases as a cause of mortality.

American Medicine (Jan. 31, 1903) says, concerning the mortality in Chicago, that during the first 17 days of January, 1903, more than one-fifth of all deaths was due to pneumonia. The deaths from tuberculosis in Chicago in 1860 were 25.28 pere 10,000 (276 deaths in 109,206 population). In 1900 they were 15.30 per 10,000 (2,599 deaths in $1,698,5 \% 5$ population), a decrease of nearly 40 per cent. (39.1) of tuberculosis mortality in the 40 years. From pneumonia the 48 deaths in 1860 represent a rate of 4.40 per 10,000 of the population; in 1900 the 3,389 deaths represent a rate of 19.95 per 10,000 , an increase of more than 350 per cent.

1. The Joursal A. M. A., June 6, 1896, p. 1113.

2. Charlotte N. C. Medical Journal, September, 1898, p. 299.
(353.4) of pneumonia mortality. The whole country shows a decrease of 20.7 per cent. of deaths from tuberculosis and an increase of $\% .4$ per cent. of deaths from pneumonia during the forty years.

What is the cause of this increase of mortality among the patients suffering from pneumonia in our time? Probably one important factor in the increased fatality in the cases of pneumonia occurring in large cities is the class of patients who are treated in city hospitals.

Many of these patients are hard drinkers, and the mortality among such persons is always very large. Another factor that has been dwelt on and has undoubtedly swelled the average of mortality has been the advent of acute epidemic influenza (commonly called la grippe). Many other causes might be adduced to explain the failure of our art in curing this disease, and the interesting query comes up whether our change of treatment and abandonment of blood letting has not been a factor in producing this discouraging result.

Let me describe a class of cases of acute pneumonia in which blood letting is not only advisable, but absolutely necessary to save the life of your patient. We will suppose, for instance, the case of a young man in vigorous health, a hearty eater, full blooded and one who perhaps, while not an habitual drinker, yet loves the good things of this life, not wisely, but too well. Such a young man is attacked with acute pneumonia, and in three, four, five or six days perhaps, you will see crape on his door, and are shocked to hear that he is dead. What is the cause of such a young man's death? In the process of inflammation which occurs, perhaps one-third, onehalf or even two-thirds of the lung tissue of your patient is filled up with a glutinous lymph which plugs up every air vesicle and thus preventing almost entirely the access of air in all the smaller bronchi. You cut into such a lung in the postmortem room and you find it solid. You drop it into water and it sinks like a piece of liver or other solid organ. Now what is the condition of that man's circulation? 'The heart, which perhaps beats normally at 65 or 70 is now beating 100,110 , or even 120,140 or 150 per minute.

Your patient's face and lips are perhaps cyanosed, his respirations are 30,40 or even 50 per minute. He lies quiet and says but little, for his breath is too precious to be wasted in words, but with imploring eyes he looks to you for help. In such a case bleed such a patient at once and you will probably save his life. What harm can you possibly do to such a patient by bleeding him? The loss of blood is nothing to him, he has too much of that in his body now for his present needs. In other words, here is an inflamed lung the aerating surface of which is diminished to one-half or one-third, or even one-fourth of its normal capacity. At the same time the heart is pumping the blood with greater force and frequency than in health into the semi-solid lung. How does this patient die? Simply because there is not sufficient oxygen brought to the lung to properly purify the impure venous blood and convert it into the life-giving arterial blood. 'The heart works harder and harder to perform the impossible task assigned to it, but finally gradually fails in power, and death speedily ensues.

Take in a case like this a pint or a pint and a half of blood from the arm and you accomplish two things, first you take away the surplus blood which is overfilling and engorging the blood vessels of the lung, and secondly you diminish the force and frequency of the heart's action, which is sending to the inflamed lung far more venous blood than it can purify. 
The objection may be made that your patient may be unable to spare such a large quntity of blood from the drain thereby made on his vitality; if so the remedy is easy. At the same time that you bleed him, or immediately thereafter, inject by hypodermoclysis under the skin of the thorax or abdomen just the same quantity of normal salt solution (1 to 1,000) as you took from your patient by bleeding.

\section{BLEEDING IN PUERPERAL ECLAMPSIA.}

The indisputable facts that puerperal eclampsia occurs most frequently in primipara and in young women in the prime of life would seem to indicate clearly that it must be caused by a toxemia resulting from deficient metabolism and the retention of effete and waste products in the body. What is the cause of this toxemia? How can it be remedied? We are strongly convinced that the cause is a very simple and obvious one, and that this disease is due to the nonassimilation of the large amount of meat and other nitrogenous foods consumed by the majority of pregnant women. After the initial stage of suffering from nausea and vomiting has passed to which many women are subject during the early months of pregnancy, the appetite is apt to become abnormally keen. Patients are encouraged to gratify this abnormal appetite by their friends, and even if the appetite should fail they are urged to eat largely, it being a popular superstition that it is necessary for them to do so in order to nourish properly themselves and their unborn offspring. Another most reprehensible practice is the prescribing by physicians of alcoholic drinks of various kinds at meal times for the purpose of stimulating the flagging appetites of pregnant women. Harm is done by this practice in two ways, first, by stimulating the appetites of these patients, inducing them to partake of more food than they require, and secondly, alcoholic drinks (beer, wine, etc.) diminish the metabolism and encourage the retention of effete matters in the body.

Two other factors entering into the causation of this disease are the neglect to take sufficient exercise in the open air and neglect to keep the skin in healthy condition by frequent bathing and brisk friction.

If the foregoing views are correct and the chief causes of puerperal eclampsia are improper diet and hygiene, the question arises, how can this disease be prevented?

It is my firm conviction, based on 47 years of continuous practice, that many of these cases can be prevented, and, of course, preventive treatment is far more important and more successful than the remedial. The following case is an illustration of preventive treatment:

Mrs. M. R., aged 22, is of healthy physique, and had always had execellent health. She engaged me Dec. 10, 1901, to attend her in her first confinement. She was at this time eight months pregnant. She was to go to Columbia Hospital for Women, which she entered Dec. 31, 1901. She complained of severe and continuous headaches, with sparks of fire before her eyes and some vertigo. Her urine was examined and showed the presence of albumin and tube-casts and a great deficiency in the amount of urea; it averaged only three to four grains per fluid ounce. She was immediately placed upon a rigorous diet, and not allowed to take more than one-third her usual allowance of food. Meat and stimulants were absolutely interdicted, and she was given thin soups and a small amount of milk and farinaceous food. For medication she was given broken doses of calomel, followed by mild saline cathartics so as to secure two or three loose movements of the bowels per day. She was also given a mixture of citrate of potash with a small proportion of potassium bromid. Under this treatment she gradually improved and the amount of urea excreted gradually increased, though it never came up to the normal amount. She was watched carefully, and, greatly to my relief, symptoms of labor set in Jan. 10, 1902. Her confinement and her convalescence were normal and uneventful.

The above preventive treatment, however, has a much wider field in the earlier months of uterogestation. The urine of every pregnant woman should be systematically examined at least once a month until the end of the term.

If albumin is found in the urine (especially if accompanied by deficient excretion of urea) it shows that the elimination of waste material is abnormally lessened; purgatives and diuretics should be given. Hydrotherapy with diminution of or total abstinence from nitrogenous food and alcohol, are also powerful adjuncts in the treatment of these patients.

But there may not be any opportunity for preventive treatment, for the patient may be already in a state of coma or in the throes of puerperal convulsions when we first see her. This is an emergency that will tax to the utmost the skill and self-reliance of the most accomplished physician. What shall we do? Shall we proceed to empty the uterus, bleed, give inhalations of chloroform or use morphia? In regard to the first treatment mentioned all authorities practically agree that if the convulsions develop during the labor, at full term, delivery should be accomplished either by version, the application of the forceps or other means as rapidly as possible. This rapid delivery of the child will very often arrest the convulsions, or if it does not do so entirely, will so mitigate them as to render the case comparatively casy of treatment.

This is not invariably the case, however, for one of the severest cases of puerperal eclampsia ever met in my experience was one in which the convulsions began after the labor had terminated satisfactorily. The labor had not been unusually severe for a primipara, but there was a smaller flow of blood from the uterus during and after the labor than is usual. The patient was a vigorous healthy woman, plethoric and with full tense pulse. The convulsions continued for 24 hours subsequent to the termination of labor, in spite of the free use of inhalations of chloroform, and the administration of chloral and morphia combined with bromids. The attending physician and myself, becoming almost desperate, finally determined to bleed her. By the dim light of a candle we bled her from the arm to the amount of 20 ounces, and there was almost instantaneous relief. The convulsions stopped at once and she made an uneventful recovery. We felt satisfied from the full and hard character of her pulse that the convulsions were continued by the blood pressure on the cerebral centers, and the result seemed to confirm this view of the case.

No one at the present day would wish to revive the old Sangrado system of indiscriminate bleeding for every disease, but it is the firm conviction of many physicians, of whom I am one, that we have been too hasty in abandoning the use of blood letting. The field of usefulness of bleeding, however, is very limited, and it is only in such cases as the one just described that we would recommend it.

That Annual Bath.-To illustrate the rôle that personal uncleanliness plays in disease among the lower classes, American Medicine telis the story of a mother who sought the aid of a physician for her sick child. A physical examination being necessary, the physician attempted to remove some of the child's clothing, but became lost and asked the mother to undress the child. She replied, "Aber, mein Gott, I have sewed it in for de Vinter." 